\title{
Transnational Body Projects: Media Representations of Cosmetic Surgery Tourism in Argentina and the United States
}

\author{
Erynn Masi de Casanova ${ }^{1}$ \\ University of Cincinnati \\ erynn.casanova $@$ uc.edu \\ Barbara Sutton \\ University at Albany, SUNY \\ bsutton@albany.edu
}

\begin{abstract}
Cosmetic surgery tourism (CST) is part of the growing trend known as medical tourism. As people in the global North travel to less affluent countries to modify their bodies through cosmetic surgery, their transnational body projects are influenced by both economic "materialities" and traveling cultural "imaginaries." This article presents a content analysis of media representations of cosmetic surgery tourism in a major country sending patient-tourists (the United States) and a popular receiving country (Argentina). The power relations of globalization appear to be played out in the media. U.S. sources assert U.S. hegemony through a discourse emphasizing the risks of CST in the global South, in contrast with medical excellence in the U.S. Argentine sources portray Argentina as a country struggling to gain a foothold in the global economy, but staking a claim on modernity through cultural and professional resources. The analyzed articles also offer a glimpse of how patient-tourists fuel sectors of the global economy by placing their bodies at the forefront, seeking to merge medical procedures and touristic pleasures. There is a gender dimension to these portrayals, as women are especially likely to engage in CST. Their transnational body projects are tainted by negative media portrayals, which represent them as ignorant, uninformed, and driven mainly by the low price of surgery overseas. Our comparative approach sheds light on converging and diverging perspectives on both ends of the cosmetic surgery tourism chain, showing that patterns in CST portrayals differ according to the position of a country in the world-system.
\end{abstract}

Keywords: Cosmetic surgery tourism, media discourses, transnational consumption, commodification of the body, U.S., Argentina

\footnotetext{
${ }^{1}$ The authors are listed in alphabetical order and contributed equally to this article.
} 
"Cut-Rate Cosmetic Surgery Lures Americans Overseas" - KDSK News, St. Louis, Missouri

"Basking on the Beach, or Maybe on the Operating Table" - The New York Times

"Turismo Médico: Bajo Costo y Alta Calidad [Medical Tourism: Low Cost and High Quality]" Clarin

"Siliconas, Tango, y lo Demás [Silicone, Tango, and the Rest]" - Página 12

Headlines of reports on cosmetic surgery tourism from U.S. and Argentine media, 2001-2010

Cosmetic surgery tourism - traveling in order to undergo cosmetic surgery - is part of the growing trend known as medical tourism, which includes both urgent and elective medical procedures. Although cosmetic surgery tourism (CST) can happen within a country, it is generally conceived of as involving international travel. For decades, wealthy elites from the developing world have traveled to the "North," usually the United States and Europe, to have elective procedures done. ${ }^{2}$ Now we are seeing the reversal of this model: people from rich countries are traveling to less affluent ones for surgery. Exact figures on how many people engage in CST are difficult to obtain, yet media and academic sources suggest that CST is becoming increasingly popular and that, as with cosmetic surgery more generally, most of the people going abroad for surgery are women (Ackerman 2010; ASPS 2010; Edmonds 2011). In contrast, plastic surgeons tend to be men. ${ }^{3}$ Countries such as Argentina, Brazil, Costa Rica, India, Mexico, and Thailand are important CST destinations; Thailand receives 400,000 medical tourists per year, and "tiny" Costa Rica 150,000 (Bookman and Bookman 2007: 3). It is estimated that in 2007, a total of 750,000 U.S. residents engaged in medical tourism, and projections for 2012 exceeded 1.6 million patients (Deloitte 2009).

Considering the number of bodies moving across borders for surgery and the potential economic impact, it is not surprising that cosmetic surgery tourism has attracted media attention. We examine how this transnational practice is portrayed by media outlets in one sending and one receiving country: the United States, a major source of these patient-tourists, and Argentina, a popular destination for them. Media representations are worthy of critical inquiry because they are often "constitutive rather than representative of common notions" (Reimers 2007: 240). Media reports help create as well as frame public response to the social or economic phenomena they describe. In light of this creative power of media, we ask: How do media reports depict travelers who go abroad for cosmetic surgery? How are the members of the medical establishment in destination countries portrayed? What kinds of messages do potential CST participants, and the public at large, receive about CST, especially about dangers and benefits?

\footnotetext{
${ }^{2}$ In one highly publicized recent case, the first lady of Nigeria died after undergoing cosmetic surgery in Spain (Knight 2005).

${ }^{3}$ For statistics on the gender composition of the American Society for Plastic Surgeons, see Gurunluoglu and Gurunluoglu 2009; to view the male-dominated roster of SACPER, Argentina's Society of Plastic, Aesthetic, and Reconstructive Surgery, visit http:/www.sacper.org.ar/00-web/miembros/; to see Costa Rica's ACCPRE, Costa Rican Association of Plastic, Aesthetic, and Reconstructive Surgery's male-dominated medical directory, visit http://www.accpre.com/directorio medico.html. The rosters of doctors from various countries affiliated with the International Society of Aesthetic Plastic Surgery can be found at http://www.isaps.org/members-by-countryalphabetical-order.html.
} 
Our analysis sheds light on the ways that transnational practices are discussed in countries differently situated in the global economy and at opposite ends of the CST chain. These representations provide social commentary on the circulation of bodies, money, and cultural ideas across national borders. We begin by situating our study in relation to the literatures on globalization and consumption, and introducing our concept of transnational body projects, to highlight how gendered bodies may be constructed (in this case literally) across and within nation-states. We bridge scholarly approaches that focus on globalization but not on bodies, or that discuss body projects without attention to their transnational dimensions. After a discussion of our content analysis method, we examine the media representations of CST in Argentina and the United States, focusing on the three necessary elements of transnational body projects: material conditions, cultural imaginaries, and social actors. In our conclusion, we sum up the links between media representations and location in the world system, as well as the class and gender aspects of these portrayals. Our comparative approach shows that patterns in CST portrayals differ according to the position of a country in the global political economy.

\section{Globalization, Consumption, and Transnational Body Projects}

The globalization of travel and communications makes medical tourism possible, allowing people to obtain information about destinations and services via internet, arrange travel and procedures, and access international transportation. These practices exemplify the "space-time compression" (Harvey 1990) that characterizes globalization. In this context, new types of travel and transnational consumption, such as CST, remind us that "spatial and temporal practices are never neutral in social affairs ... they always express some kind of class or other social content" (Harvey 1990: 239). Cosmetic surgery tourism creates new kinds of classed and gendered international travelers and consumers who are drawn to the lower costs of procedures resulting from global economic disparities between nation-states.

The democratization of travel in the twentieth and twenty-first centuries has led to tourism becoming one of the world's largest industries (MacCannell 1976; Crick 1989; Urry 1990; UNWTO 2011). Whereas international tourism was once the monopoly of elites, it is increasingly seen as a desirable part of Western middle-class lifestyles. Tourism is a form of transnational consumption, and tourists are the modern consumers par excellence, engaging in conspicuous recreational activities as members of the "leisure class" (MacCannell 1976). Economic and cultural globalization resulted in novel patterns of consumption (Harvey 1990; Kondo 1997; Miller 1997; García Canclini 2001; Wilson 2004), and diverse motives for international travel exemplify these shifts (Munt 1994).

Cosmetic surgery tourism illustrates the emergence of new kinds of travelers/consumers. While still more privileged than other categories of transnational travelers (e.g. impoverished migrants, refugees), the new cosmetic surgery tourists are usually not elite, but middle- and lower-middle-class individuals aspiring to the "improved" bodies that elites can achieve through cosmetic surgery and other expensive treatments in their home countries. Though some forms of tourism, such as "sex tourism," have catered specifically to men's bodies and desires (Wonders and Michalowski 2001), women traveling in CST reverse such trends in international travel.

Cosmetic surgery has been characterized as a consumption practice increasingly aimed at the general population, and not just targeted at bodies deemed "sick" or "abnormal" (Holliday and Cairnie 2007; Pitts-Taylor 2007). Cosmetic surgery - and by extension CST - is part of a 
larger social and cultural process of "turning the patient into a consumer" (Pitts-Taylor 2007: 28). The ideal cosmetic surgery patient, as portrayed in both news and entertainment media, is the supposed "informed, rational consumer" of the capitalist market (Pitts-Taylor 2007: 154). This consumer is expected to make rational choices about products and practices that will presumably result in the successful modification of her/his body, which is often a central dimension of identity in contemporary societies (Shilling 2003). Recasting cosmetic surgery as a form of consumption allows for an excavation of the "political economies underlying identity projects" (Pitts-Taylor 2007: 33). This move is particularly relevant in the case of CST, as the practice cannot be fully understood without examining the economic layers that shape this phenomenon.

Favorable exchange rates and lower prices for medical procedures in places like Argentina are important CST motivators, making surgery accessible for those who cannot afford these procedures in more affluent countries such as the United States. If we view class as linked to lifestyle, appearance, and bodily habits (Weber 1946 [1924]; Bourdieu 1984), CST can be seen as blurring class boundaries by allowing non-elite people access to elite bodily forms of consumption. U.S. cosmetic surgery patients are willing to make financial sacrifices and go into debt in order to pay for their procedures (Gimlin 2000; Gimlin 2007), and CST offers a more economical alternative and/or an opportunity to undergo multiple procedures for a low price.

The positioning of cosmetic surgery patient-tourists as transnational consumers points to the importance of incorporating the body in analyses of globalization. Indeed, patient-tourists travel to modify their bodies, and this "work on the body constitutes not only a project of the self" but a project with transnational dimensions (Molz 2006: 7). This is the case both in a material and discursive sense: 1) CST exemplifies how concrete practices on the fleshly body are enabled through transnational border crossings, which are in turn propelled by economic conditions or materialities, and 2) with increased contact between cultures via media, migration, and travel, representations and conceptions of beauty and the body travel across national boundaries, and infuse CST practices and expectations. Thus we offer the notion of CST as a transnational body project. This idea carries forward theories of the body as a "project which should be worked out and accomplished as part of an individual self-identity" (Shilling 2003: 4; see also Brumberg 1998). The transnational body project is a (re)fashioning of individual bodies that makes use of resources that stretch across national borders. CST is just one type of transnational body project, and we use this example to sketch the outlines of the material, cultural, and interpersonal aspects of such projects. Theories of globalization tend to overlook bodies, and theories of the body and embodiment often leave out the extra-local context; the transnational body project concept is useful precisely because it links bodies and globalization.

Scholarly literature on globalization usually focuses on macro-economic processes: trade agreements, global production sites, financial markets, and international financial institutions. These processes are not just abstract economic exchanges, but depend on, enlist, affect, and reconfigure human bodies. These bodily dimensions of globalization, however, have received less scholarly attention. Attending to bodies in relation to global trends (Harcourt 2009; Mackie and Stevens 2009; Sutton 2010; 2012), including the movement of bodies across borders to undergo cosmetic surgery, can help advance our understanding of "transformations of the intimate in the context of global restructuring" (Runyan and Marchand 2011: 239-240). For instance, in his study of CST in South Africa, Andrew Mazzaschi (2011) argues not only that the neoliberalization of health care enables CST, but that this practice actually produces notions of bodies' value in projects of bodily modification. In other words, CST involves connections 
between the large-scale forces of globalization and the realm of the body, desire, and subjectivity.

Bodies are central to globalization processes. Drawing on Marxist perspectives, theorist David Harvey (2000: 27) underscores the significance of the "laboring body" to global capitalist production (see also Harvey 1998; Callard 1998). Feminist scholarship adds to such analyses by bringing into focus the intersections of various inequalities - including gender, class, race, sexuality, and nation - that shape bodily practices in a globalizing world. For instance, feminist literature on the global factory shows the entanglement of such inequalities in the disciplining of the bodies of low-income, racialized women working in export processing zones in the global South (Freeman 2000; Salzinger 2003; Bank Muñoz 2008). We also learn about the violence against marginalized women's bodies - including sexual violence and "feminicide" - in global production hubs, such as the maquiladoras area on the Mexico-U.S. border (Fregoso and Bejarano 2010). Surrogacy arrangements, through which relatively affluent couples in the global North rent the wombs of poor women in the South, throw into stark relief the intersecting inequalities that fuel these practices (Twine 2011). Feminists show how diverse women's bodies are alternately enmeshed in, absent from, or disempowered in much of the development discourse that permeates global and domestic economic policies (Harcourt 2009).

Here we are particularly interested in the transnational dimensions of embodied forms of consumption, such as CST, and their attendant inequalities. Businesses can profit by catering not only to classed, gendered, sexualized, and racialized bodies embedded in particular nation-states, but also to those able to travel internationally. In the age of globalization, consumer goods link geographical sites and connect diverse people in a chain of hierarchically organized interdependence. Through CST, transnational flows and interdependencies are set in motion, including the circulation of information, culture, capital, technology, and people. In this way, we can think of CST and other transnational body projects as "global assemblages," constellations of practices that "articulate" broad cultural, political, and economic changes (Collier and Ong 2005: 4). The patient-tourist's journey literally results in a transformed body, and this transformation requires that a myriad of institutions, economic conditions, and governmental policies be in place.

In addition to bringing the body into our understandings of transnational processes, the study of CST can reveal social dynamics that are relevant to sociology of the body. Research on cosmetic surgery tends to focus on seemingly contained national settings, examining either one country or using cross-national comparisons. More recent works about medical tourism, including cosmetic surgery, sex reassignment, and reproductive tourism, are starting to shed light on the transnational dimensions of bodily surgical/medical practices. ${ }^{4}$ Our work contributes to this budding field of research by analyzing media representations of CST in two countries involved in these exchanges at opposite ends of the transnational chain.

Attention to the media illuminates an understudied aspect of CST: the public conversations that surround the phenomenon, which may shape this medical tourism sector and participants' practices. For example, potential patient-tourists may learn about CST through the media, shaping their perceptions. Although an analysis of media sources is an indirect approach to understanding relevant dimensions of CST, this analysis offers insights about how cultural contexts and the position of different countries in the world system affect prevailing

\footnotetext{
${ }^{4}$ See, for example, Ackerman 2010, Aizura 2009, Jones 2008, Martin 2009, Turner 2010; also, the Winter 2011 issue of Signs and the June/September 2011 issue of Body \& Society.
} 
representations, which may in turn motivate people's behavior. Our concept of transnational body projects emerged from this analytical process, as we gained a glimpse of the material, cultural, and interpersonal aspects of transnational relations that enable this type of bodily transformation. That is, like other transnational processes, CST connects "materialities," "imaginaries," and embodied social actors (Sassen 2007: 2).

We consciously use the term "tourism" in our exploration of CST, and refer to these travelers as "patient-tourists," in recognition of their dual role as individuals seeking medical treatment and visitors to destination countries. In scholarship on medical tourism, some have objected to the term "tourism" to describe people seeking fertility treatment or other types of medical services (Martin 2009; Bergmann 2011; Gilmartin and White 2011; Kangas 2011). We use the terms tourism and patient-tourists to emphasize the international travel aspect of CST, the elective nature of the surgeries, and the cultural fantasies about destinations that may affect travelers' expectations. For some time, luxury resorts around the world had already been including services dedicated to the upkeep of the physical body (e.g., massage, facials, detoxification procedures, and other spa-like services), practices that blur the lines between care of the body for aesthetic versus health purposes, and between body-maintenance and touristic activities.

\section{Methods}

Although figures on the prevalence of CST are scattered and often not separated out from statistics on medical tourism, it is commonly agreed that the U.S. is one of the main sending countries and that Argentina is a popular destination for patient-tourists in the Western hemisphere (Bookman and Bookman 2007). Argentina was an ideal country to use as a case study not only because of its popularity among CST patient-tourists, but also because of our familiarity with the cultural, social, and economic context. One author (Barbara Sutton) is an Argentine citizen who has been doing social research there for the past decade, and the other (Erynn Masi de Casanova) has conducted research on Latin American and Latino/a media since 2001. Similarly, as U.S.-based scholars with research experience there, we had the access and competency to analyze sources from the United States, selected due to its prominence as a sending country. Thus we compared media reports from both countries and from similar types of sources during the same period of 2001-2010. Because of our comparative focus and expertise in Latin American issues, only articles that mentioned Latin American CST destinations were selected, including those that also mentioned other destinations along with Latin America. We only included sources that mentioned cosmetic surgery tourism specifically, even though some also addressed local cosmetic surgery or medical tourism more broadly.

We focused on representations of CST in media and news reports that were directed to a general audience rather than more specialized groups. For example, advertisements and CST websites specifically target prospective and actual cosmetic surgery patients, whereas media reports are disseminated to the public at large. This was important, as we wanted to examine the emerging public discussions of CST as a social and economic phenomenon, discussions that any literate person might read about or participate in. To identify articles from U.S. news outlets (newspapers, magazines, and their online sites), we conducted searches in the Lexis-Nexis database and monitored news coverage with a Google News E-mail Alert. We decided to expand our search criteria to include local broadcast news reports after finding that they accounted for a 
significant proportion of media reports on this topic. The Argentina-produced media reports were found by performing searches in the online archives of two major national newspapers, Clarin and La Nación, as well as the smaller nationally circulating newspaper Página 12 and national magazines. Because we were interested in the portrayal of practices and people and not just in stories of abstract global processes, we paid particular attention to articles that included either interview quotes or narratives from people directly involved in CST (e.g., doctors, patients, travel agents).

We used qualitative content analysis, beginning with what has been called "directed" analysis, in which texts are coded according to key themes drawn from theory or previous research (Hsieh and Shannon 2005). Theories of globalization and bodies led us to focus on coding actors (patients, doctors, and others), the material/economic dimensions of this practice (such as cost), and the representation of "other" cultures and countries. We simultaneously made use of "conventional" content analysis, in which "coding categories are derived directly from the text data" (Hsieh and Shannon 2005: $1277^{5}$ ); in this way, certain repeated themes, such as the "horror stories" of surgeries gone wrong and the construction of patient-tourists as good or bad consumers, emerged as important for the representation of CST. The unit of analysis was the news article or report, and we coded fragments of text as well as assessed the overall message of the report. In all, we conducted content analysis on 28 U.S. media reports, which we supplemented with four additional internet-only and entertainment-oriented sources that we analyzed in less detail. We also analyzed 30 articles from Argentina, bringing the total number of media reports examined to 58 .

This sample gives a good idea of what types of public conversations about CST were taking place over the past decade (2001-2010) in these two countries. After an initial read of the articles, we devised a coding scheme in order to qualitatively analyze their content and the messages they conveyed about CST. We coded articles for their discussion of the driving forces behind the expansion of CST (both individual motivations for travel and macro-scale factors); outcomes of CST (with CST "horror stories" emerging as a subsequent sub-category); doctors as participants in CST; and patient-tourists as participants in CST. Significant themes (e.g. "horror stories," emphasis on costs, quality of doctors) were quantified for comparison. Both authors conducted the analysis of both sets of articles, and in the few instances in which our assessment differed, we came to an agreement or modified categories through discussion. We then compared the U.S. and Argentina sources to identify similarities and differences in their depictions of CST. All translations from the original Spanish to English in this text were done by the authors.

Content analysis reveals the portrayals offered by one of the key social institutions shaping public perceptions on CST: the media. Analysis of media coverage helps trace some key developments in the field of CST and identify its participants. Our method enabled us to indirectly access a variety of perspectives from social actors involved in or providing opinions on the practice of CST, but more importantly, to compare the public discussions of CST in the two countries on both ends of the cosmetic surgery tourism chain. We now turn to the description and analysis of how media reports on CST represent: 1) materialities, or the economic imperatives of CST; 2) imaginaries, or the cultural fantasies and ideologies that enable or discourage CST, and 3) key social actors (patient-tourists and doctors). Together, these three areas comprise entwined dimensions of transnational body projects.

\footnotetext{
${ }^{5}$ For examples of this approach, see Casanova 2003 and Lutz and Collins 1993.
} 


\section{Representations of Cosmetic Surgery Tourism}

\section{Materialities: Economic Imperatives}

Economic conditions set the stage for CST on both sides of the travel chain. The sources analyzed offer a variety of economic reasons for the emergence and growth of CST as an individual embodied practice and an industry. Both Argentine and U.S. sources $(91 \%$ of the articles analyzed) emphasized the relative low cost of cosmetic surgery in receiving countries as a chief engine of this trend. U.S. articles mention lower wages, lower training costs, and lower prevalence of malpractice lawsuits driving down the cost of surgeries in global South destinations. The large majority of the articles from Argentina (83\%) implicitly or explicitly mentioned low cost as a motivating factor, and over half of these referred to the impact of the 2001 economic crisis, which led to the devaluation of the Argentine currency and made cosmetic surgery there relatively inexpensive for foreign visitors. The magnitude of cost savings is exemplified by a La Nación article, which stated that breast implants cost about $\$ 10,000$ in the United States, but only \$2,300 in Argentina (Ríos 2009).

CST's expansion has been facilitated by macro-economic restructuring in receiving countries (Turner 2010; Sengupta 2011). Scholarly and media reports mention not only the role of economic crisis but also of neoliberal development strategies in the rise of medical tourism. CST is made possible by a free-market health care model, even as it reinforces and benefits from the disparities between private and public health systems. For example, Edmonds' (2011) research on Brazil shows that local and international medical residents use public hospitals (serving poor and working-class people) as training grounds for their cosmetic surgery skills before they transfer to the more highly paid private sector. Furthermore, while expensive private health services and facilities are directed to international tourists, they are unaffordable to local populations marginalized by race, gender, and class (Turner 2010; Mazzaschi 2011, Sengupta 2011). In one of the media reports we analyzed, the facilities serving patient-tourists are even referred to as "export-oriented hospitals," (Pierce 2006) mimicking, with a twist, other global production sites (e.g., export processing zones).

Catering to patient-tourists requires changes in medical and building infrastructure, and some medical centers are turned into hospital-hotels, with amenities appealing to international patients. The New York Times reports on the luxurious Bumrungrad Hospital in Thailand, where

a foreign visitor could expect five-star hotel extras: meet-and-greet service at the Bangkok airport, a multilingual personal escort to take him from test to test during physicals. And the rooms themselves were luxe and, by American standards, cheap -- some just $\$ 54$ a night. There were 250 -thread-count cotton sheets and complimentary toiletries in baskets woven by Thai hill tribes. The hospital brought in chefs from Bangkok's most glamorous restaurants -- a new one each month -- to cook patients' menus. For customers who found the cuisine too exotic, a McDonald's was installed in the lobby's food court. (Talbot 2001)

While patient-tourists may not be elite in their countries of origin, they can still receive first-class treatment and feel at home, the description suggests. In some ways, the dynamic described 
replicates an extractive/colonizing relationship between members of an affluent country and those in a poor one. ${ }^{6}$

Yet it is not only the characteristics of the destination's medical facilities (or touristic attractions) that are mentioned in the examined media. Both U.S. and Argentine articles also referred to deficiencies in the health systems of sending countries in the global North. For instance, uninsured or underinsured people in the United States cannot afford the expensive health costs in their own country, while patients in countries with socialized health coverage, such as the UK or Canada, face long waiting periods to undergo some surgical procedures. ${ }^{7}$ This dimension of the media reports reflects the non-elite character of many patient-tourists, people who do not have sufficient disposable income to completely bypass the problems of health care access in their own countries. While the characteristics of the destination countries may be seen as "pull" factors, the inadequacies of the sending countries systems constitute "push" factors, encouraging individuals to pursue a transnational body project, that is, a body transformation out of reach at home.

Governmental economic policies are also cited as playing a role in facilitating or discouraging the practice of CST. Six of the Argentine articles (20\%) present CST as part of a broader economic development strategy, in which tourism is a central dimension. For instance, the national government launched the program Medicina Argentina to promote the country as a major world player in medical tourism, aiming to attract 100,000 patients annually (Ríos 2009). This program involves combining a business orientation with a health care approach. The blurring of categories of health care and business or of patient and consumer are already under way in largely privatized medical systems such as the U.S. one (Pitts-Taylor 2007). In such contexts, medical care is often presented as a consumer good, even a luxury, to be bought and sold in the market, available to those with the means to pay. The emergence of medical tourism takes this confusion of categories to a global scale. Forty of the reports we examined (69\%) use language that (directly or indirectly) identifies CST as an industry, business, or market, with some discussing vacation tours and medical procedures offered as bargain "packages" and "all inclusive" services. A Frommers article suggests that CST mimics aspects of fast food service, reporting on a CST operator whose "general inquiry form with drop down menus is like ordering an operation and expecting them to ask if you'd like fries with that!" (Heelan 2005).

Economic imperatives - individual financial motivations, business profit-seeking behavior, economic disparities between countries, and government development strategies - are frequently mentioned in the sources that we examined and they constitute the engine that drives CST. Without these economic conditions the transnational body project would not exist. These materialities are important, but, as we will see, the circulation of cultural fantasies and ideologies matter, too.

\footnotetext{
${ }^{6}$ The disparities that mark this relationship include Thailand's more meager health care resources along various dimensions, such as personnel. For example, according to data published by the World Health Organization (2011), the number of physicians per 10,000 people in Thailand is 3.0; for the U.S. it is 26.7 .

${ }^{7}$ See Turner (2010) for a scholarly analysis of these and other macro trends influencing the proliferation of medical tourism.

${ }^{8}$ The concept of "push" and "pull" factors have been used to explain transnational migration trends (Massey et al. 1994), but could also be applied to trends in cosmetic surgery tourism.
} 


\section{Imaginaries: Traveling Cultural Fantasies and Ideologies}

The increase in CST to Latin America is related to circulating imaginaries that enable the commodification of bodies, cultures, and places. The body as a consumer project and product in advertising and media is a global phenomenon. Similar images of ideal feminine beauty circulate in the U.S. and Latin America, and the Latina/Latin American body is increasingly incorporated into beauty ideals (Casanova 2004). This incorporation can be seen in the frequent victories by Latin American contestants in global beauty pageants such as Miss Universe, and in the increased visibility in the U.S. of Latina "beauties" including Jennifer López, Salma Hayek, and Sofía Vergara. Scholars have critiqued the misrepresentation of Latinos/as in the U.S. media, and the sexualized and homogenizing portrayals of Latinas in particular, which reinforce stereotypical perceptions (Rodríguez 1997). Because of the global reach of current communications, particularly those that are U.S.-based, such images have more than a local impact. The fact that U.S. and Latin American popular culture often present similar images of beauty, in some cases representing the same celebrities as ideal beauties, may partly facilitate CST. There seems to be a common language of beauty, and an agreement on what is attractive that likely makes patient-tourists more comfortable in contracting with Latin American surgeons. High rates of cosmetic surgery in many Latin American CST destinations, like Argentina, may also contribute to a sense of safety or confidence among prospective and actual patient-tourists. If not universal, beauty may at least be translatable across borders in this new global context.

Ideas about "other" cultures play a role in individual decisions to embody a particular kind of beauty through CST. Along with hegemonic Western ideals valorizing youthful, slim, and firm bodies, traveling fantasies about "exotic" places and peoples appear in the media reports we analyzed. Stereotypical (racialized/sexualized/gendered) portrayals of different world regions help promote CST. Thus we learn about "sexy" Buenos Aires (Byrnes 2009), the "stunning women" of Brazil (many benefiting from the "helping hand" of cosmetic surgery; Heelan 2005), or Colombian women "renowned for their beauty" who embrace a "pro-plastic surgery" context (de Leon 2006). Here the fantasy seems to be the ability of individual patienttourists to capture the exotic/sexy/beautiful qualities of people (particularly women) in the global South while still being able to return to the North, with all its benefits. ${ }^{9}$ These ideas are reinforced through the language in ten of the U.S. articles, which refer to the "lure" or "alluring" features of cosmetic surgery tourism - wording that connotes seduction, temptation, or attraction to the forbidden.

Beauty cultures, both local and transnational, matter in terms of circulating media images of desirable bodies, but also with respect to the recipes for achieving particular kinds of bodies. At the local level, the prevalence of some procedures in destination countries (e.g. the popularity of cosmetic surgery in Argentina or the portrayal of Thailand as a paradise for sex reassignment) adds to the attraction for certain forms of medical tourism. At the same time, the global proliferation of "extreme makeover" reality shows ${ }^{10}$ (mentioned in a couple of articles) may compound the influence of low prices and limited time in the decision of some patients to undergo multiple surgeries. In these ways, traveling cultural ideas help fuel increasingly

\footnotetext{
${ }^{9}$ See Aizura (2009) for an analysis of cosmetic surgery and gender reassignment tourism in Thailand. According to the author, circulating ideas about "Thai beauty' represent a form of idealized femininity that is both desired as exotic and culturally appropriated" by international tourists interested in changing their bodies (305).

${ }^{10}$ These are television shows in which participants undergo multiple surgeries and other beauty treatments.
} 
transnational body projects. Individual bodies can be literally produced in multiple sites across national borders according to prevailing beauty standards and in places imagined as beautiful or sexy. Or so goes the promise. As we will see later, media sources alert us that there is a danger for the "bad" patient-tourist: damaged rather than perfected feminine bodies.

In addition to beauty ideals, cultural differences and similarities are also drawn upon to explain why individuals prefer certain places for cosmetic surgery tourism destinations. Just over ten percent of the U.S. sources speak of the gentle and friendly character of people in destination countries such as Costa Rica and Thailand (presumably resulting in more personable care). Likewise, cultural difference emerges from the juxtaposition of Argentine articles' representations with regard, for example, to punctuality. People from Argentina are supposedly "used to waiting" (La Nación 2009) and medical tourists appear to be "demanding about schedules" (Pandolfo 2005). In addition, Argentine doctors maintain that "the foreign patient is not accustomed to the humanized and warm treatment they receive in Argentina, or to discussing personal issues in the consultation" (Pandolfo 2005). Positive perceptions of cultural difference presumably attract patients to Argentina as a site for cosmetic surgery. Sometimes, cultural similarity is presented as the magnet; for example, U.S. sources speak of migrants to the United States returning home for surgery, or people of Latin American descent or with relatives in the area going to Latin America for surgical procedures because of cultural and linguistic affinities.

In some cases, cultural difference is presented as discouraging cosmetic surgery tourism to some destinations. One article in the Argentine newspaper Clarin subtly implies that Argentina is a better destination than India by portraying the latter as a country "known for its dirtiness" - a concern for prospective patient-tourists - while still clarifying that "the main private hospitals in India offer the same standards of cleanliness as in the Occident" (Dhillon 2005). Prospective patient-tourists reading this description would have to imagine moving through the "dirtiness" to get to the pristine hospital, and decide whether it was worth it. Referring to the advantages of medical tourism in Argentina, an official from the national institute of tourism is quoted in La Nación as saying, "There is also an issue of cultural proximity [of Argentina] with the United States, Europe and other Latin American countries... For a norteamericano [North American] it is a sensitive situation to go to receive treatment in a country like India, that does not share the language, or religion or have the same views on the mystery of life" (Ríos 2009). Ethnocentrism and cultural stereotypes seem to inform the portrayal of different locales, favoring some destinations over others. A transnational body project is a very personal venture, so the right cultural match is critical for a successful experience, these representations imply.

On the tourism side of the equation, cultural and natural attractions play a key role in CST, and these amenities are often packaged as alluring fantasies. Six U.S. articles (21\%) emphasize the appeal of "exotic" destinations, and $43 \%$ of the U.S. sources mention cultural attractions and idyllic natural settings, including hotels close to beaches, lagoons, and lush vegetation. In Argentina, the wonders of Buenos Aires and its tango tradition, along with excursions to other parts of the country (e.g. Patagonian glaciers, Iguazú Falls, wine country) are mentioned. An Argentine article summarizes this perfect combination with the title, "Silicone, Tango, and the Rest" (Nudler 2004). Similarly, U.S. articles mention other combinations, such as "Surgeon and Safari" in South Africa, ${ }^{11}$ surgery and visits to the Taj Mahal in India, or cosmetic

11 See Mazzaschi (2011) for an analysis of medical tourism drawing on ethnographic work on the Johannesburgbased company, Surgeon and Safari. 
treatments and immersion in the natural beauty of the Caribbean. Tourism brings money, and the key is to attract this source of income by emphasizing and developing what might be desirable to modern tourists: "Meet Buenos Aires, the wonderful and incredible city of Evita and tango: direct flight... and eyelid surgery, liposuction, lifting or breast implants" (Roa 2006). In an interview with Página 12, actor and politician Hector Bidonde, critically comments that in addition to tango and futbol (soccer), cosmetic surgery is now part of the Buenos Aires "brand" (Cabrera 2008). And it is precisely this "brand" of transnational body projects that is being marketed internationally.

\section{The Social Actors}

Globalization is often discussed in abstract terms, with attention paid to markets and economic flows. Yet markets are designed and regulated by people, and are made up of people and their decisions. Capital and corporate products move across borders, but so do human beings. In studying CST, we focus on media depictions of what actual people are doing (or having done to them). The sources we analyzed provide images and narratives of some of the social actors who enable the industry. Entrepreneurs and intermediaries in the tourism, beauty, and medical fields transform cultural and economic practices in order to make this brand of tourism possible. The players include translators, beauticians, personal assistants, travel agents, clinic directors, advertisers, doctors, and of course, patient-tourists. Here we examine two key groups of people brought together in CST and commonly portrayed in popular media accounts: patient-tourists and doctors.

Patient-Tourists. The patient-tourist blends an interest in undergoing medical procedures and the desire to enjoy a visit to a vacation spot. The magic promised is to turn an unpleasant, or at best neutral, medical intervention into a positive experience, framed as an expansion of choice. The patient-tourist is expected to weigh the choices available, like "good" consumers do, and embark on a tourism/medical journey, but-as the U.S. sources we analyzed emphasize - at her/his own risk. While the language of consumer/patient-tourist may seem gender-inclusive, the articles we examined tend to feature or refer to women in this role, and some of the articles that portray both men and women do so in a different light. The patient-tourist embodies a transnational social relation that brings together the tourist industry, medical systems, and beauty enterprises. These coordinated efforts make possible gendered transnational body projects.

Content analysis of media representations of CST in the U.S. and Argentina reveals a tendency to separate "good" patient-tourists from "bad" ones. Moral evaluation of cosmetic surgery patients in general has been documented in the United States by Pitts-Taylor (2007), and our research shows that such discussions have crossed borders, particularly in reference to women. The U.S. news reports, and to a lesser extent, those from Argentina, equate being a good patient-tourist with being a good consumer.

In the U.S. media depictions, the single most important action a patient-consumer can undertake prior to going abroad for surgery is research. More than half of the U.S. sources emphasized due diligence on the part of the prospective traveler before deciding on CST. According to these articles, "travelers who seek care abroad can follow several measures to boost the chances it will be adequate," including checking out doctors' credentials and training and learning about the facilities where procedures are conducted (Doheny 2006). Readers are also advised to "find out about your procedure, recovery time, and possible complications" (Bradley 2010) - and reports in the U.S. sample often describe these complications in gory detail. This 
type of research takes time, and, media reports remind prospective patient-tourists, "it is difficult to sue over surgery gone wrong in a foreign hospital" (Kerr 2006). As one article puts it, "You have to be a smart consumer; don't be afraid to ask questions when talking to the hospital or physician $[\ldots]$ do your homework before booking that trip [...] Be a very cautious consumer" (Bradley 2010). Good CST patients are smart, cautious, and conduct research before making travel arrangements.

When transnational body projects go wrong, as the U.S. articles warn is possible, it is often patient-tourists who are blamed for not doing enough research. The following exchange took place on a 2007 episode of The Montel Williams Show, featuring a patient-tourist who "says she went overseas to get plastic surgery and almost died":

Montel [talk show host]: You didn't research the facility?

Carla: No, or the mortalities.

Montel: Or the mortality rate.

Carla: Mm-hmm.

Montel: Didn't even ask questions about it on the Internet? "Does anybody ever know anybody who's got a surgery at this place?" Didn't do that, right?

Carla: Nope... I felt safe.

The good patient-tourist is implicitly defined in opposition to the bad patient-tourist, who is a bad consumer, and does not get recommendations or seek enough information prior to engaging in CST. Even in news reports that portray patient-tourists (women) with "botched" surgeries sympathetically, they are blamed for not researching their options thoroughly enough. In the story of one woman who had an unsuccessful surgery in the Dominican Republic, "there was no research, it was based totally on the word of [her] hairdresser... [she] says word of mouth was enough, along with the price tag" (Corderi 2005). Bad consumers, then, in addition to not investigating prior to CST, prioritize price over bodily safety and quality. "Horror stories" (Bookman and Bookman 2006) - defined here as descriptive, even gruesome, narratives of transnational body projects gone wrong - show up in nearly one quarter of the U.S. media reports. The patient-tourists featured in the horror stories in our sample were all women.

In many of the sources we analyzed, the news media and U.S. doctors deliver the same message about the dangers of CST and the responsibility of patient-tourists for their outcomes. The president of the American Society for Aesthetic Plastic Surgery is quoted as saying (in reference to patient-tourists who need to get unsuccessful surgery outcomes "fixed" after returning home): "these are angry, disappointed people... you feel badly for them, but you feel they've been dumb too" (Talbot 2001). In one local news report, a Texas doctor states: "you get on the [U.S./Mexico] border and you got the dregs. You got the people who can't make it in the city and they're saying cheap, cheap, cheap, quick, quick, quick. Pay a price they never expected to pay" (Zigman 2005). Interestingly, this quote does not clearly distinguish the doctors or businesspeople who take advantage of patients from the patients themselves, painting all participants in CST negatively. However, in some of the articles it is clear that people whose primary consideration is the cost of surgery are ridiculed and portrayed as bad consumers. Indeed, a classist undertone is apparent in words such as "bargain-basement" and "cut-rate" used to describe CST procedures. If bad consumers travel abroad in order to afford to alter their bodies, then good consumers are those who can afford to pay for top-quality surgeries in the United States. 
Individual patient-tourists and their stories receive less attention in the news reports from Argentina. However, the good/bad or smart/dumb consumer dynamic also appears in these sources. The mix of admiration and contempt for patient-tourists that emerges in the Argentine reports may reflect diverse perspectives, but it may also point to ambivalence about foreign visitors and their activities in relation to the local culture and context. One Argentine doctor praises foreign consumers for their savvy: "the patients from countries with higher levels of education really look into who will be caring for them" (Para Tí 2010). Another physician is quoted as saying, "foreign patients usually require the résumé of the surgeon, and, if possible, ask an Argentine friend about the quality of the professional" (Roa 2006). Here CST patienttourists coming to Argentina are portrayed as sophisticated, well-educated, and able to obtain the information they need prior to planning their trip.

Still, some Argentine sources, like the U.S. reports, also present an image of the patienttourist as negligent or unintelligent. One article, narrating the positive experience of a mother and daughter who traveled from Colorado to Buenos Aires for surgery, features the following interview excerpt: "Did they know anything about the country before coming? "Nothing. Only what we saw in the movie Evita" (Piotto 2007). This report goes on to poke fun at CST patienttourists: "It is amazing, the trust with which they submit themselves to the operating room even when they know absolutely nothing about the country... there are even some who find out, once in Buenos Aires, that Argentina is not the capital of Brazil!" (Piotto 2007). The message is clear: these foreigners are not savvy consumers. In another article, an Argentine doctor opposes CST as "one more business that takes advantage of people's irrationality... in the future, they'll go to the moon or Mars for treatment" (Román 2009). The president of the Argentine Society of Plastic Surgery believes that patient-tourists have unrealistic expectations. One cannot move from one country to the next for medical treatment, he says, "without knowing the doctor" (Himitian 2002). He goes on to say that he does not believe that "thinking people" will get surgery just because it is offered along with travel opportunities (Himitian 2002). It is clear that for this doctor, "thinking people" do not blithely combine surgery with international travel.

In addition to being naïve, the bad consumer is also portrayed as dishonest. When a Spanish patient-tourist died in Buenos Aires in 2008, newspapers and the physicians and family members they interviewed were hesitant to place blame on the surgeon. However, as in the U.S. cases, the unlucky patient-tourist was vulnerable to criticism. One doctor stated that "sometimes the patients hide information about their health status because they are afraid the surgery will be canceled" (Página 12 2008). He also complained about "anorexic women, people with depressed immune systems," and "people on psychopharmeceuticals" who wanted to get surgery (Página 12 2008). There seemed to be a gendered angle to his portrayals of "bad" cosmetic surgery patients: "many women think that this is like going to the hair salon, they pick the cheapest, look for doctors who minimize all [the risk] and don’t explain anything" (Página 12 2008).

In contrast, in the context of a practice largely associated with women, when men undergo cosmetic surgery they are more likely to be described in positive terms, for example, as more knowledgeable of the country, as "daring" to undergo the medical procedure, and as successful businessmen or professionals (e.g. Piotto 2007, Selser 2006). In a couple of the articles that depict both male and female patients, competition in love or business is an important motivation for men, while women seem to just desire to look beautiful, and appear more likely to be willing to undergo more invasive surgeries or multiple interventions. One article's (Ríos 2010) assertion that men are more "fearful" than women to go under the knife is somewhat neutralized by also saying that "they prefer less invasive procedures" (i.e. given that invasive 
procedures may produce harm, perhaps it is not bad to be afraid). In one La Nación (2002) article, the stereotypical image of a woman as an avid shopper - a patient who goes on a shopping "raid" despite her recent breast surgery and hip treatment - is contrasted with the case of a man who undergoes surgery to repair his nose, damaged in a car accident. Furthermore, it is men's desire to look younger and better that seems to require more of an explanation, whereas women's concern with looks is perhaps taken for granted.

There is one major difference between the depictions of patient-tourists in the U.S. versus the Argentine media: the greater prevalence of "horror stories" in the U.S. reports. The two patient-tourist deaths mentioned in the Argentine sample are presented in a straightforward way. In contrast, the U.S. reports were more likely to feature detailed narratives of patient-tourists' post-surgical troubles, some accompanied by explicit images not for the faint of heart. The absence of "horror stories" in the Argentine articles alters the context in which ideal types of good and bad consumers, wise or unwise transnational body projects, are elaborated. In the U.S. sources, bad consumers - those who don't "do their homework" before going abroad for surgery - reap the consequences of their laziness in the form of bodily infections, disfigurement, gangrene, or even death. These are failed transnational body projects. The Argentine sources also divide consumers into good and bad, or smart and dumb, but the majority of these patienttourists seem to go home happy, their transnational body projects fulfilled. In this way, the Argentine sources support the national goal of tourism promotion.

Doctors. Among CST service providers, doctors are the most essential, as they have a direct hand in the outcome of transnational body projects. In both countries, the media reports tend to mostly feature or refer to male doctors. So while the patients portrayed tend to be women, those operating on their bodies tend to be men. A gender hierarchy is thus implied in the media representations, particularly when pairing the "bad" female (embodied) patient-tourist and the authoritative (disembodied) voices of doctors commenting on the practice.

We can also think of the doctors' practice in transnational terms. They are at the intersection of local opportunities and global trends, bridging the distance between people from different nation-states. Some are transnational doctors in the sense that they travel physically and have professional investments across national boundaries. For instance, a doctor who has a cosmetic surgery practice in Manhattan also travels to Jamaica to treat U.S. patients who spend a "Botox weekend" in a resort-hospital in Jamaica (Valhouli 2002). Doctors in destination countries are more place-bound in terms of their practice, but there may still be transnational dimensions to their work: the reports tell of doctors trained in the U.S., or who seek international credentials or advertise on the worldwide web.

The doctors performing CST operations are ready to function in a globalized arena. These transnational body projects require transformations in both the kind of medical procedures offered and the kind of vacation planned, for example, when doctors modify their normal procedures for the convenience of traveling patients. An Argentine doctor reports: "We adopt techniques for patients who cannot stay to have the stitches taken out: instead of sewing we use a spray that sticks or sutures that reabsorb themselves." He described medical techniques which "[r] equire the visitor to be in the city for ten days at the most" (Himitian 2002). The vacation aspect of the trip, such as visits to tourist attractions, is worked around the demands of the surgical interventions.

Many articles (36\% of the U.S. sample and $57 \%$ of the Argentine sample) refer to the good quality of care, doctors, and facilities in receiving countries, including their growing efforts 
to cater to and live up to the standards of more affluent countries (but, as we shall see, there is a marked difference in the two countries' portrayal of doctors engaged in CST). Thirty-nine percent of the U.S. articles mention that many medical professionals in receiving countries have even been trained in the global North. The implicit assumption seems to be that the quality of medical knowledge and practice in wealthier countries is inherently superior. At the same time, $18 \%$ of U.S. articles mention as an advantage the traditions or inclusion of alternative care that is compatible with patient-tourists' needs for rejuvenation and relaxation (for example, Thai-style massage and spa treatments). The Argentine sources, as compared to the U.S. ones, place greater emphasis on the high quality of care offered to patient-tourists, taking nationalistic pride in Argentina's "medical tradition" (Clarin 2005) and "first class" medical professionals (Ríos 2009). U.S. doctors are also involved in a less direct way in the U.S. reports, frequently weighing in on the appropriateness and possible risks of CST.

In comparing the media coverage in the two countries, we encountered glaring differences in representations of the surgeons who operate on patient-tourists. The depictions of Latin American doctors in the U.S. sources were generally unfavorable, and often damning. In contrast, the Argentine articles praised surgeons involved in CST, citing the high quality of medical care in the country as a key incentive for foreign patient-tourists. Though the representations of superior versus inferior doctors may be partly about competition for customers between nations, these discourses seem also to be rooted in longer standing ideologies and positioning of the countries in the world-systemic hierarchy. The Western medical establishment claims superiority over other medical traditions and the implicit expectation for professionals to emulate European and U.S. doctors reinforces dichotomies of civilized/barbaric, modern/ backward that discursively uphold the U.S. as a dominant nation in relation to others. ${ }^{12}$ These assumptions are implicit in the U.S. reports' graphic depictions of transnational body projects gone awry, which function as cautionary tales. Conversely, Argentina emerged as a country castigated by an economic crisis, but one that held on to distinctive strengths, the reports suggest. Argentine sources' positive portrayal of the country's doctors fits well with a more generalized sense of national pride documented by other scholars, particularly in relation to Argentina's technological and scientific advances (see, e.g., Sautu et al. 2008).

The U.S. sources were more likely to depict "horror stories." These include reports of patients whose "blood levels started dropping" and "stitches started opening," or who suffered "a rare bacterial infection" or experienced "fatal events" after their cosmetic surgeries abroad (Zigman 2005). One article is accompanied by a picture of a person's badly scarred belly. In a New York Post article, a woman who had surgery in Argentina, and was left with a "drastically abbreviated nose," states that "[i]t was cored, scooped out" (Graham 2001). Another woman who underwent surgery in the Dominican Republic reported that during the operation she "literally felt their hands inside [her] stomach" (Corderi 2005). The U.S. articles reiterate the difficulty of getting U.S. doctors to repair surgical mistakes made overseas. Some articles raise the question of whether U.S. doctors have self-interested motives when they oppose CST, but then this possibility is rejected by the more typical narrative that points to the risks patients face. One article states: "American doctors... simply may not like the idea of losing business" (Moeller 2010). Another notes that "some critics believe American surgeons might have an agenda. After all, bargain basement prices are luring customers away" (Zigman 2005). A third report referred

\footnotetext{
${ }^{12}$ See Baronov (2009) for a discussion of these issues in the African context.
} 
to CST as "foreigners poaching their [U.S. doctors'] clients" (Dickerson 2008). Still, these articles did not explore such possibilities, devoting much more text to the potential risks of CST.

"I was butchered." So states the recipient of a "botched tummy-tuck" in the Dominican Republic at the beginning of one U.S. news article (Waller 2005). The surgeon in this highlypublicized case was later accused of causing several deaths, including those of some U.S. citizens (Corderi 2005; Waller 2005). The figure of the Latin American surgeon as butcher appears in several U.S. news reports. Some articles use implied or explicit references to animals to highlight the ways that doctors' mistreatment dehumanizes patient-tourists and disfigure their bodies. One woman who had rhinoplasty in Argentina described the results as a "pig's nose" (Byrnes 2009). According to a woman who had medical problems after returning home from surgery in Mexico, a U.S. surgeon whom she consulted "refused to treat me, and he actually told my mother I should go see a vet[erinarian]" (Zigman 2005). While it was a U.S. doctor who made this comment, the origin of the dehumanization of the patient-tourist's body lay in the Mexican surgeon's hands. One patient-tourist "says she was prescribed a skin cream for her scars that is not even intended for humans" (Corderi 2005). The foil for the negligent Latin American surgeons is the shocked U.S. doctor who is asked to "fix" these mistakes. "I have never seen a worse case of gangrene anywhere," claims one Texas surgeon, describing the condition of a patient-tourist who underwent cosmetic surgery in Mexico and later died. Some U.S. doctors turn away patients whose surgeries abroad have gone wrong, according to these articles, again questioning the intelligence of patient-tourists who choose to undergo procedures in "backward operations run by physicians with questionable credentials" (Gómez 2005).

One gruesome horror story from the U.S. highlighted unsterile conditions (including a buzzing fly in the operating room) in a Mexican clinic (Gómez 2005). The clinic is run by a man who calls himself a doctor, despite not having a medical license. In one disturbing scene, a nurse began to shave a Texas woman's pubic hair to prepare her for a liposuction. The patient-tourist said, "no, no liposuction, no liposuction" and then complained to the "doctor" about this mistake. He said that the nurse had misunderstood him and gone to the wrong patient's room. Then, "pretending to pick her shaved hair off the floor and placing it over his lip, he joked, 'Oh, I just wanted to use it [pubic hair] as a mustache. I'm sorry, honey" (Gómez 2005). Here medical incompetency is made more objectionable by the fake doctor's inappropriate behavior, resonating with U.S. stereotypes about Latin American men as being lascivious or hypersexual. Bad consumers end up with bad doctors, and failed transnational body projects are the result, U.S. reports such as this one implicitly suggest.

The portrayal of surgeons attending CST patient-tourists could not be more different in the Argentine sample. The majority of these articles (57\%) list Argentina's high-quality medical care and well-trained surgeons as a driving factor in the increase of CST. In a typical description, one newspaper article claims that Argentina has surgeons who are "first-class, able to conduct medical and surgical procedures comparable to those of any developed country" (Ríos 2009). Both Argentina and U.S. sources state that 1 in 30 Argentine citizens has undergone cosmetic surgery, meaning that surgeons have had the opportunity to develop a great deal of experience and are informed of the latest surgical developments and innovations. In Argentina, doctors serving CST patient-tourists are presented as competent and ethical. One surgeon's anecdote exemplifies this: "A week ago a lady came from the United States who had arranged a plastic surgery through a medical tourism company... they had told her that everything was okay, but when I asked her to do some routine tests, it turned out that she had a severe coronary risk, and I had to tell her that there was no way I could operate on her" (La Nación 2008b). Rather than 
being out to make a quick buck, this surgeon is portrayed as thorough and responsible, doing what was best for the patient.

In contrast, while four Argentine sources report fatal results due to complications and warn about some of the risks of cosmetic surgeries, the stories are more matter-of-fact rather than gruesome or sensational. The sources that report on patients' deaths have straightforward titles such as "A Woman Died During a Breast Implant" (La Nación 2008a) or "A Tourist Died in a Porteña [Buenos Aires] Clinic After a Breast Implant" (Página 12 2008) or "A Spanish Woman who Came to the Country to Undergo Plastic Surgery Died" (Clarin 2008). In the case of a Spanish patient-tourist who died in Buenos Aires after going under the knife, news reports did not portray the surgeon unfavorably, but took the position of waiting to find out all of the facts. The story was not written up in the media as a morality tale or a warning to potential patienttourists, the tone often taken in the U.S. sources that discussed surgeries gone wrong. Yet, a couple of these articles show concern about how the death of patients could affect Argentina's international reputation. For example, a La Nación (2008a) article notes that sectors of the Spanish media covered the death of the Spanish patient as "an emergent case of what they defined as "cheap sanitary tourism in Argentina."

In U.S. sources, the Latin American doctors seen as responsible for negative outcomes came across as callous, negligent, and cruel. Non-U.S. doctors were implicitly treated with suspicion (thus the instruction to potential patient-tourists to do their homework). This presentation stands in opposition to the characterization of U.S. doctors in these sources as benevolent experts whose warnings about the dangers of CST are based not on economic greed but sincere concern for patients' safety. In Argentine media reports, doctors treating CST patienttourists (as well as the handful who are quoted as criticizing the practice) are described and presented as well-trained and responsible. These different representations are probably linked to the economic aspect of CST - U.S. doctors lose and Argentine doctors win in CST. However, the negative representations of foreign doctors in the U.S. sources also line up with and thus reinforce existing stereotypes about Latin Americans as being less civilized and less moral. While these notions may serve to discourage CST, as we have seen, other sets of stereotypes and cultural fantasies on beauty, places, and cultures may act to promote the practice.

Pairing media sources from both sending and receiving countries adds nuance to understandings of CST portrayals. This comparative approach helps to explain why some scholars find that "media coverage often minimizes health risks" (Edmonds 2011: 298) and others observe that "news media coverage of 'medical tourism' commonly addresses risks related to obtaining treatment abroad" (Turner 2010: 463). In our study, both assessments are true, but what we find is that location in a global hierarchy of nations matters for how risks, as well as other features of the practice of CST, are represented by the media.

\section{Conclusion}

Despite more than a decade of discussions in the popular press, medical tourism - and cosmetic surgery tourism specifically - is only relatively recently receiving attention from scholars. The existing research has tended to focus directly on the experiences of the people involved, or alternatively, on macro-level trends. Here we add a needed perspective on media representations of CST. The media have a pedagogical dimension, and the lessons in this case are not only about CST per se, but also about broader accounts of transnational practices that in turn influence 
people's attitudes and behaviors. In reporting about CST, media sources reflect and construct national pride, cultural stereotypes, and a sense of one's country in relation to others in the world system. These reports illustrate the public conversations on CST. Potential patient-tourists may get the idea of CST in the first place, or have their perceptions about the practice shaped, through the media. Since most people are not cosmetic surgery patient-tourists, surgeons, or others directly involved with the industry, the main contact that the general public has with this phenomenon is probably through media exposure.

In juxtaposing the reports from countries at opposite ends of the CST chain, a picture of CST as a contested cultural and economic terrain appears. In addition to varied reports on individual experiences, the articles we analyzed also mention a host of developments in tourism, medical practice, and governmental policies in the Global North and South. What does this comparative focus reveal about CST portrayals? While we indirectly learn about multiple economic, social, and cultural layers shaping transnational body projects, the comparison yields two central - and related - findings: one is about globalization and the other is about gender relations and ideologies (which intersect with other systems of inequality, such as class and raceethnicity).

With respect to globalization, our comparative focus reveals that patterns in CST portrayals differ according to the position of a country in the global political economy. These representations may be partly grounded in the logic of economics (nations and businesses competing for customers), and they also point to longer histories of how nations see themselves and relate to others in an unequal world-system. That is, the power relations of globalization appear to be played out in the media. The U.S. strives to assert its hegemony, while peripheral or semi-peripheral countries, such as Argentina, struggle to gain a foothold in the global economy. Indeed, the Argentine economic crisis sharply undermined the country's position in the worldsystem, but the Argentine articles also tell a story of a nation that still has cultural resources and technical expertise to draw on, and to feel proud of - resources that could rival any first-world nation. The U.S. articles deliver a message about U.S. superiority by giving voice to its presumably excellent doctors. Echoes of U.S. and Western hegemony permeate perceptions about CST in several articles.

We also learn about ordinary people as key players in globalization processes. Patienttourists fuel sectors of the global economy by placing their bodies at the forefront, seeking to merge medical procedures and touristic pleasures. As social actors involved in globalization, these patient-tourists are different from multinational corporation executives, dispossessed migrants and workers, or globetrotting social movement activists. They have similarities with other tourists, but their transnational body projects are what motivate their border crossings. Through the media reports we get an idea of how these transnational body projects link macro and micro dynamics. These projects assemble global economic transformations, broadly circulating ideologies, and individual subjectivity. For many of these non-elite patient-tourists, bodily expectations cannot be fulfilled within the borders of their own country, and yet, those who go abroad are often portrayed as problematic in the U.S. sources. Are they, to some extent, perceived as betraying the nation? After all, their journey exposes the flaws of the "best medical system in the world" (touted by some U.S. politicians). Yet in these negative portrayals, a moralizing tale of personal failure is more prevalent. If patient-tourists do not have the means to transform their bodies in the U.S., then a transnational journey will not get them what they were unable or unwilling to obtain at home, as it may result in one of the gruesome outcomes epitomized by the media "horror stories." 
The patient-tourists' transnational body projects are symbolically dashed in the negative and gendered media portrayals of CST, in which they are represented as ignorant, uninformed, and driven mainly by the low price of surgery overseas. The bad consumer/patient-tourist is thus someone who does globalization incorrectly. There is a gender aspect to the implicit rejection of middle-class and lower-middle-class women's transnational body projects. Clifford wrote about the binary opposition "naturalized along the lines of gender" of "female, domestic space versus male travel" (1997: 84-85). Freeman has argued convincingly that "travel, with its embodiments of worldliness, adventure, physical prowess, and cultural mastery, is widely constructed as a male pursuit" and that the movement of women across borders, whether for pleasure or work, can be seen as a "challenge to the traditionally gendered configuration of space and motion" (2001: 1018). The mostly female CST participants deemed bad consumers do not do enough research before blithely tripping across the globe to alter their bodies. They are not elites, with whom international travel (and cosmetic surgery, for that matter) has traditionally been associated. In the narratives featured in many U.S. media sources, and some Argentine articles, these transgressions can lead to miserably failed transnational body projects. In contrast, the authoritative voices of doctors (which have particular weight in the articles from both countries) tend to be male, reinforcing gender and class hierarchies.

The entwined threads of gender and globalization are also apparent in yet another aspect of CST representations: the benefits that destination countries boast. The media portrayals are not just about the "failed" transnational body projects of travelers from the global North. When looking at the Argentine reports, we see the efforts of a country in the global South trying to claim a stake in globalization by exalting its modern culture, including the technical competency of its professionals, the high quality of its services, and the resourcefulness of its entrepreneurs. Interestingly, the "successful" body projects of local women are also enlisted to further make the case. Reports implicitly draw on gendered national myths about Argentine women's superior beauty and explicitly mention the popularity of cosmetic surgery among Argentines as perhaps reassuring evidence of good results. Local gendered bodily practices and ideas are deployed as resources to bolster transnational business opportunities, in this case CST.

The examination of media sources enables simultaneous access to the public conversations in two countries at opposite ends of the hemisphere and of the CST chain. Future studies can further examine the interlocking components of transnational body projects materialities, imaginaries, and social actors - through approaches that incorporate direct observation and interactions with the people involved. To date, micro-level accounts have not systematically linked individuals' experiences to the public conversations about CST that have been occurring in the media of both sending and receiving countries. This article aimed to provide an introduction to the content of these conversations, as a first step toward studying media's role in the construction of transnational body projects.

\section{Acknowledgements}

The authors gratefully acknowledge the insightful comments and suggestions offered by Amy Lind, Elizabeth Borland, and three anonymous reviewers, which helped improve this article. The project also benefited from Elmira Alihosseini's research assistance. 


\section{References}

Ackerman, Sara L. 2010. "Plastic Paradise: Transforming Bodies and Selves in Costa Rica's Cosmetic Surgery Tourism Industry," Medical Anthropology 29(4): 403-423.

Aizura, Aren Z. 2009. "Where Health and Beauty Meet: Femininity and Racialisation in Thai Cosmetic Surgery Clinics." Asian Studies Review 33 (September): 303-317

ASPS [American Society of Plastic Surgeons]. 2010. "Cosmetic Surgery Tourism Briefing Paper." $\quad$ http://www.plasticsurgery.org/news-and-resources/briefing-papers/cosmeticsurgery-tourism.html

Bank Muñoz, Carolina. 2008. Transnational Tortillas: Race, Gender, and Shop-Floor Politics in Mexico and the United States. Ithaca: Cornell University Press.

Baronov, David. 2009. "The Role of Historical-Cultural Formations within World-Systems Analysis: Reframing the Analysis of Biomedicine in East Africa." Journal of WorldSystems Research XV(2): 147-166.

Bergmann, Sven. 2011. "Reproductive Agency and Projects: Germans Searching for Egg Donation in Spain and the Czech Republic." Reproductive BioMedicine Online 23(5): 600-608.

Bookman, Milica Z. and Karla R. Bookman. 2007. Medical Tourism in Developing Countries. New York: Palgrave Macmillan.

Bookman, Richard J. and Milica Z. Bookman. 2006. "The Downside of Medical Tourism." The Miami Herald, February 26.

Bourdieu, Pierre. 1984. Distinction: A Social Critique of the Judgment of Taste. Cambridge, MA: Harvard University Press.

Bradley, Fleur. 2010. "Medical Tourism: Are the Savings Worth the Risk?" San Francisco Chronicle (SFGate.com), March 29.

Brumberg, Joan Jacobs. 1998. The Body Project: An Intimate History of American Girls. New York: Vintage.

Byrnes, Brian. 2009. "Nip and Tuck on a Budget in Argentina." CNN.com, September 10.

Cabrera, Hilda. 2008. "El poder burgués odia al pueblo y desprecia al hombre." Página 12 , March 11.

Callard, Felicity J. 1998. "The Body in Theory." Environment and Planning D: Society and Space 16(4): 387-400.

Casanova, Erynn Masi. 2004. "No Ugly Women: Concepts of Race and Beauty among Adolescent Women in Ecuador." Gender \& Society 18(3): 287-308.

-----. 2003. "Women's Magazines in Ecuador: Re-Reading 'la Chica Cosmo." Studies in Latin American Popular Culture 22: 89-102.

Clarín. 2005. "Polonia, nuevo paraíso europeo para los amantes de las cirugías estéticas." June 1.

------. 2008. "Murió una mujer española que vino al país a hacerse una cirugía plástica." February 7.

Clifford, James. 1997. Routes: Travel and Translation in the Late Twentieth Century. Cambridge, MA: Harvard University Press.

Collier, Stephen J. and Aihwa Ong. 2005. "Global Assemblages, Anthropological Problems." Pp. 3-21 in Global Assemblages: Technology, Politics, and Ethics as Anthropological Problems, edited by A. Ong and S. J. Collier. Malden, MA: Blackwell.

Corderi, Victoria. 2005. "Plastic Surgery Tourism? Dangers of Going under the Knife on the Cheap." MSNBC, March 18. 
Crick, Malcolm. 1989. "Representations of Tourism in the Social Sciences: Sun, Sex, Sights, Savings, and Servility." Annual Review of Anthropology 18: 207-344.

de Leon, Sergio. 2006. "Tourists Heading to Colombia for Plastic Surgery." USA Today, March 14.

Deloitte. 2009. "Medical Tourism: Update and Implications." http://www.deloitte.com/assets Dcom-UnitedStates/Local\%20Assets/Documents/us chs Medical Tourism 111209 web.pdf

Dhillon, Amrit. 2005. "En masa, los occidentales vuelan a la India para hacerse cirugías plásticas." Clarin, October 31.

Dickerson, Marla. 2008. "Ticket to Treatment." The Los Angeles Times, November 2.

Doheny, Kathleen. 2006. "A Little Sightseeing, a Little Face-lift." The Los Angeles Times, January 29.

Edmonds, Alexander. 2011. “Almost Invisible Scars': Medical Tourism to Brazil." Signs (36) 2: 297-302.

Freeman, Carla. 2000. High Tech and High Heels in the Global Economy: Women, Work, and Pink-Collar Identities in the Caribbean. Durham: Duke University Press.

------. 2001. "Is Local: Global as Feminine: Masculine? Rethinking the Gender of Globalization." Signs: Journal of Women in Culture and Society 26: 1007-1037.

Fregoso, Rosa-Linda and Cynthia Bejarano, eds. 2010. Terrorizing Women: Feminicide in the Américas. Durham, NC: Duke University Press.

García Canclini, Néstor. 2001. Consumers and Citizens: Globalization and Multicultural Conflicts. Minneapolis: University of Minnesota Press.

Gilmartin, Mary and Allen White. 2011. "Interrogating Medical Tourism: Ireland, Abortion, and Mobility Rights." Signs 36(2): 275-280.

Gimlin, Debra. 2000. "Cosmetic Surgery: Beauty as Commodity." Qualitative Sociology 23(1): 77-98.

-----. 2007. Body Work: Beauty and Self-Image in American Culture. Berkeley: University of California Press.

Gómez, Lisa Marie. 2005. "The Ugly Road to Beauty: One Woman's Harrowing Quest for Plastic Surgery." $M S N B C$, June 8.

Graham, Jessie. 2001. "Plenty Flocking South for Fun and a Facelift." The New York Post, March 11.

Gurunluoglu, Raffi and Aslin Gurunluoglu. 2009. "Do Plastic Surgeons Have Cosmetic Surgery?" Plastic and Reconstructive Surgery 124(6): 2161-2169.

Harcourt, Wendy. 2009. Body Politics in Development: Critical Debates in Gender and Development. London: Zed Books.

Harvey, David. 1990. The Condition of Postmodernity. Cambridge, MA: Blackwell Publishing.

-----. 1998. "The Body as an Accumulation Strategy." Environment and Planning D: Society and Space 16(4): 401-421.

------. 2000. "The Work of Postmodernity: The Laboring Body in Global Space." Pp. 27-51 in Identity and Social Change, edited by J.E. Davis. New Brunswick, NJ: Transaction Publishers.

Heelan, Charis Atlas. 2005. "Cosmetic Surgery Tourism: A Tummy Tuck in Thailand, a Breast Augmentation in Brazil." Frommers, September 6.

Himitian, Evangelina. 2002. "Otro imán turístico: las cirugías estéticas." La Nación, September 1. 
Hsieh, Hsiu-Fang and Sarah E. Shannon. 2005. "Three Approaches to Qualitative Content Analysis." Qualitative Health Research 15(9): 1277-1288.

Holliday, Ruth and Allie Cairnie. 2007. "Man Made Plastic: Investigating Men's Consumption of Aesthetic Surgery." Journal of Consumer Culture 7(1): 57-78.

Jones, Meredith. 2008. Skin Tight: An Anatomy of Cosmetic Surgery. Oxford: Berg.

Kangas, Beth. 2011. "Complicating Common Ideas about Medical Tourism: Gender, Class, and Globality in Yemenis' International Medical Travel." Signs 36(2): 327-332.

Kerr, Kathleen. 2006. "Tourism \& Treatment." Newsday, September 26.

Knight, Sam. 2005. "Nigerian First Lady Dies after Cosmetic Surgery." The Times, October 24.

Kondo, Dorinne. 1997. About Face: Performing Race in Fashion and Theater. New York: Routledge.

La Nación. 2002. "Otro imán turístico: las cirugías estéticas. Testimonios for export." September 1.

------. 2008a. "Murió una mujer durante un implante mamario." February 6.

------. 2008b. "Cuáles son los riesgos de la intervención." August 3.

------. 2009. "Tenía muy buenas referencias de la Argentina." October 25.

Lutz, Catherine A. and Jane L. Collins. 1993. Reading National Geographic. Chicago: University of Chicago Press.

MacCannell, Dean. 1976. The Tourist: A New Theory of the Leisure Class. New York: Schocken Books.

Mackie, Vera and Carolyn S. Stevens. 2009. "Globalisation and Body Politics." Asian Studies Review 33: 257-273

Martin, Lauren Jade. 2009. "Reproductive Tourism in the Age Globalization." Globalizations (6)2: 249-263.

Massey, Douglas, Joaquín Arango, Graeme Hugo, Ali Kouaouci, Adela Pellegrino, and J. Edward Taylor. 1994. "An Evaluation of International Migration Theory: The North American Case." Population and Development Review 20(4): 699-751.

Mazzaschi, Andrew. 2011. "Surgeon and Safari: Producing Valuable Bodies in Johannesburg." Signs 36(2): 303-312

Miller, Daniel. 1997. Capitalism: An Ethnographic Approach. Oxford: Berg.

Moeller, Philip. 2010. "Growing Reasons to Consider Medical Tourism." U.S. News \& World Report, February 12.

Molz, Jennie Germann. 2006. "Cosmopolitan Bodies: Fit to Travel and Travelling to Fit." Body $\&$ Society 12(3): 1-21.

Montel Williams Show, The. 2007. "The Price of Perfection." Aired August 10, 2007. CBS Studios.

Munt, Ian. 1994. "The Other Post-Modern Tourism: Class, Travel, and the New Middle Classes." Theory, Culture, and Society 11: 101-123.

Nudler, Julio. 2004. "Siliconas, tango y lo demás." Página 12, July 11.

Página 12. 2008. "Una turista murió en una clínica porteña tras un implante mamario." February 7.

Pandolfo, Malu. 2005. "Lo que se desea mejorar: Cirugías." La Nación, July 14.

Para Tí. 2010. "El auge del turismo estético." August 9.

Pierce, Olga. 2006. "Analysis: Cashing in on Healthcare Trade." United Press International, March 13.

Piotto, Alba. 2007. "Bisturí tour: viajar rejuvenece." Clarin, March 4. 
Pitts-Taylor, Victoria. 2007. Surgery Junkies: Wellness and Pathology in Cosmetic Culture. New Brunswick, NJ: Rutgers University Press.

Reimers, Eva. 2007. "Representations of an Honor Killing: Intersections of Discourses on Culture, Gender, Equality, Social Class and Nationality." Feminist Media Studies 7(3): 239-255.

Ríos, Sebastián. 2009. "La Argentina busca atraer pacientes de otros países." La Nación, October 25.

-----. 2010. "La Argentina, en el top ten en cirugías plásticas." La Nación, December 5.

Roa, Mariano. 2006. "Las cirugías estéticas son el nuevo boom turístico porteño." Clarín, November 7.

Rodríguez, Clara E., ed. 1997. Latin Looks: Images of Latinas and Latinos in the U.S. Media. Boulder, CO: Westview Press.

Román, Valeria. 2009. "Se unen clínicas privadas para impulsar el 'turismo médico." Clarín, September 10.

Runyan, Anne S. and Marianne H. Marchand. 2011. "Conclusion: Restructuring the Intimate, the Local, and the Global." Pp. 239-244 in Gender and Global restructuring: Sightings, Sites, and Resistances, edited by M. H. Marchand and A. S. Runyan. New York: Routledge.

Salzinger, Leslie. 2003. Genders in Production: Making Workers in Mexico's Global Factories. Berkeley: University of California Press.

Sassen, Saskia. 2007. "Introduction: Deciphering the Global." Pp. 1-18 in Deciphering the Global: Its Scales, Spaces, and Subjects, edited by S. Sassen. New York: Routledge.

Sautu, Ruth, Carolina Najmias, and Gabriela S. Plotno. 2008. "Identidad y ciudadanía. El orgullo de ser Argentino." Pensares 5: 681-704.

Selser, Claudia. 2006. “Cuánto cuesta sentirse lindo?” Clarín, May 14.

Sengupta, Amit. 2011. "Medical Tourism: Reverse Subsidy for the Elite." Signs 36 (2): 312-319.

Shilling, Chris. 2003. The Body and Social Theory. London: Sage.

Sutton, Barbara. 2010. Bodies in Crisis: Culture, Violence, and Women's Resistance in Neoliberal Argentina. New Brunswick, NJ: Rutgers University Press.

------. 2012. "Body." Pp. 111-116 in Encyclopedia of Globalization, edited by G. Ritzer. Malden, MA: Wiley-Blackwell.

Talbot, Margaret. 2001. "Case Study: Vanity; Location: Bangkok." The New York Times, May 6.

Turner, Leigh. 2010. "Medical Tourism' and the Global Marketplace in Health Services: U.S. Patients, International Hospitals, and the Search for Affordable Health Care." International Journal of Health Services 40(3): 443-467.

Twine, France Winddance. 2011. Outsourcing the Womb: Race, Class, and Gestational Surrogacy in a Global Market. New York and London: Routledge.

UNWTO [United Nations World Tourism Organization]. 2011. UNWTO Tourism Highlights: 2011 Edition. UNWTO. http://mkt.unwto.org/en/content/tourism-highlights.

Urry, John. 1990. The Tourist Gaze: Leisure and Travel in Contemporary Societies. Thousand Oaks, CA: Sage Publications.

Valhouli, Christina. 2002. "Sun, Fun, \& Plastic Surgery?" Forbes, October 17.

Waller, Nikki. 2005. "Cheap Plastic Surgery Abroad Can Turn Costly, Even Deadly." The Miami Herald, March 18. 
Weber, Max. 1946 (1924). "Class, Status, and Power." Pp. 180-195 in From Max Weber: Essays in Sociology, edited by H.H. Gerth and C. Wright Mills. New York: Oxford University Press.

Wilson, Ara. 2004. The Intimate Economies of Bangkok: Tomboys, Tycoons, and Avon Ladies in the Global City. Berkeley: University of California Press.

Wonders, Nancy A. and Raymond Michalowski. 2001. "Bodies, Borders, and Sex Tourism in a Globalized World: A Tale of Two Cities-Amsterdam and Havana." Social Problems 48 (4): 545-571.

World Health Organization. 2011. World Health Statistics 2011. http://www.who.int/whosis/whostat/EN WHS2011 Full.pdf

Zigman, Leisa. 2005. "Cut-Rate Cosmetic Surgery Lures Americans Overseas." KDSK News, May 20. 